\title{
PARA QUE PRECISAMOS DO CONTEÚDO DISJUNTIVO? ${ }^{1}$
}

\author{
Ernesto Perini-Santos (UFMG) \\ epsantos@fafich.ufmg.br
}

Resumo: a idéia que existe um conteúdo comum à percepção e à mera aparência da percepção parece natural: ter uma ilusão não é outra coisa senão ter uma experiência que é subjetivamente indistingüível da percepção, e isto pode ser explicado pela identificação do conteúdo comum aos dois casos. Contra a postulação de um estado mental comum à percepção e à ilusão, alguns autores como P. Snowdon e J. McDowell propuseram uma teoria disjuntiva do conteúdo sensorial. Se um sujeito tem a impressão de perceber algo, ou bem ele percebe de fato, ou é para ele como se ele percebesse. Se esta teoria evita um estado mental "disponível para a experiência nos casos em que há engano e naqueles em que não há engano" (McDowell), o recurso à concepção disjuntiva do conteúdo não é necessário para tanto. Apresento três argumentos contra a teoria disjuntiva da percepção. O primeiro argumento é que não é certo que a teoria disjuntiva possa ser útil na explicação da experiência perceptiva, tanto do ponto de vista da primeira pessoa, quanto do ponto de vista da terceira pessoa. Em seguida, ela não é uma teoria estável do conteúdo perceptivo. Ao considerarmos o desenrolar da experiência no tempo, o interesse de um conteúdo disjuntivo parece bem menos claro, os membros da disjunção vão rapidamente se distinguir. Finalmente, parece-me que a consideração de alguns aspectos da diferença entre a percepção efetiva e pelo menos alguns casos de ilusão perceptiva sugerem um outro caminho para explicar como a percepção nos põe em contato com o mundo.

Palavras-chave: percepção, conteúdo disjuntivo, objetividade, John McDowell 
Ernesto Perini Santos

A idéia que existe um conteúdo comum à percepção e à mera aparência da percepção parece natural: ter uma ilusão não é outra coisa senão ter uma experiência que é subjetivamente indistinguível da percepção, e a explicação deste fato pela identificação do conteúdo da percepção nos dois casos parece vir facilmente à mente. Se este modo de apresentar as coisas não é um explanandum da teoria, está muito próximo disso, se associado a uma imagem do objeto da percepção como transparente ao sujeito: um sujeito não erra acerca do objeto da sua percepção. Se o sujeito erra num julgamento perceptivo, ou se algo se lhe aparece de um modo diferente do que é de fato, isso não pode ser em virtude de um erro acerca do objeto de sua percepção. Como este tipo de erro é possível, o objeto de sua percepção é apreendido quer exista de fato algo a ser apreendido ou pensado, quer não exista nada que seja como o sujeito percebe. O conteúdo da percepção é assim neutro em relação ao mundo. Esta imagem da percepção se transfere para o pensamento singular, que não é outra coisa senão a utilização do conteúdo mesmo da percepção na atividade racional do julgamento, de tal modo que o que disse sobre a percepção cabe ao pensamento singular: se se trata de fato de um pensamento singular, não parece haver espaço para o engano do sujeito acerca do seu objeto ${ }^{2}$. A explicação da falibilidade da percepção humana parece decorrer naturalmente da distância entre aquilo com que entramos em contato ao perceber algo e o mundo, ao passo que mantemos a infalibilidade do sujeito acerca daquilo que é seu objeto de pensamento e percepção.

John McDowell chama este conteúdo comum à percepção e à mera ilusão de percepção 'máximo denominador comum' (highest common factor), "o que está disponível para a experiência nos casos em que há engano e naqueles em que não há engano" (what is available to experience in the deceptive and the non-deceptive cases alike) (McDOWELL, 1998, p. 386), diz 
McDowell, não é a única possível, e não é certo que ela seja de fato bem motivada. Neste artigo, apresentarei uma caracterização desta posição e a crítica a ela que levou à teoria disjuntiva do conteúdo da percepção. Procurarei mostrar que, embora a crítica apresente boas razões para se abandonar a teoria do tipo descrito acima, a teoria disjuntiva do conteúdo pode ela mesma ser criticada, em parte por razões análogas às que levaram ao abandono da teoria do máximo denominador comum (doravante, 'teoria MDC').

\section{II}

Uma versão da teoria MDC pode ser apresentada do seguinte modo. Na percepção, um objeto o causa um estado cognitivo no sujeito que é relativo a $o$, que $o$ como parte de seu conteúdo. Imaginemos que um objeto $o$ cause num sujeito $S$ um estado no qual pareça a $S$ que $o$ é $F$ - chamemos um estado deste tipo 'estado-F'. Pode ocorrer que $S$ esteja num estado-F, isto é, num estado no qual o lhe parece ser $F$, sem que este estado tenha sido causado por $o$, ou pelo fato de $o$ ser F. Ambas situações serão indistinguíveis para $S$, ex hypothesi, mas apenas uma delas corresponde à percepção de $o$. Esta possibilidade explica a falibilidade dos nossos sentidos: um sujeito pode se enganar em seus julgamentos feitos a partir de um estado-F, que pode ou não ser causado por um objeto que parece ser de tal ou tal modo ao sujeito. O sujeito estará, no entanto, certo da base experiencial do seu julgamento, isto é, ele não se engana quanto ao conteúdo da sua experiência, ou quanto ao fato de estar num estado-F. A inferência da experiência de um estado$F$ ao julgamento de que o é $F$ é em geral correta, o julgamento resultante é em geral verdadeiro, mas o que a falibilidade dos nossos sentidos nos ensina é que um tal julgamento também pode ser falso. O estado-L é mais acessível ao sujeito do que a experiência do objeto ele mesmo, e por esta razão um tal estado pode ser dito a base experiencial de julgamentos relativos 
às situações encontradas na experiência ordinária. Esta base experiencial é comum aos casos de percepção e de ilusão - o estado-L sendo individuado por seu conteúdo, isto é o mesmo que dizer que o conteúdo da experiência da percepção e da ilusão é o mesmo.

Como mostra McDowell, esta linha de raciocínio não é a única possível. Não é necessário supor que julgamentos sejam feitos a partir de uma base à qual teríamos um acesso mais seguro do que ao julgamento ele mesmo. Pode-se em particular recusar que haja uma base experiencial, independente da percepção, que sirva, por exemplo, de critério a partir do qual julgamentos sobre a experiência são feitos ${ }^{3}$. Há pelo menos dois modos de se recusar este tipo de argumento. $\mathrm{O}$ primeiro argumento consiste em observar que nós não temos a experiência de uma tal base perceptual de julgamentos. Como diz Paul SNOWDON, "se você está em dúvida se o julgamento expresso por 'isto é uma lâmpada' é verdadeiro, você também estará em dúvida se você está vendo uma lâmpada” (2002, p. 161). Um sujeito que julga estar num determinado estado-F julga ao mesmo tempo que um estado de coisas é como o estado-F lhe apresenta ser, ou inversamente, como diz Snowdon, um sujeito que está em dúvida se está num determinado estado-F, também estará em dúvida se as coisas são como lhe aparecem ser neste estado. Se um tipo de julgamento não é mais acessível ao sujeito do que o outro, não há por que supor que um seja a base do outro.

Há um segundo argumento contra este tipo de teoria: a suposição que fazemos julgamentos sobre a experiência a partir de uma base que pode estar descolada do mundo torna ininteligível como nossa percepção nos põe em contato com o mundo. Explicando casos em que há ilusão, a teoria do máximo denominador comum (MDC) torna difícil a explicação de casos que não são enganadores (McDOWELL, 1998, p. 371-372). Esta estratégia, relativamente usual na epistemologia, consiste em recusar uma teoria por suas conseqüências céticas; um cé- 
tico, claro, pode sempre argumentar que este procedimento é circular ${ }^{4}$. Veremos que a explicação da percepção ela mesma, independentemente da motivação epistemológica, leva a uma conseqüência que não parece compatível com este desengajamento do mundo.

Uma teoria alternativa à do MDC, sugerida por HINTON num artigo de 1967 (1967, p. 217-227) e desenvolvida por Snowdon e McDowell, consiste em propor que a experiência tem um conteúdo disjuntivo. Segundo esta teoria, quando parece a um sujeito $S$ que algo é $F$, então ou bem existe um objeto que parece a $S$ ser $F$, ou bem é para $S$ como houvesse alguma coisa que lhe parece ser $F^{5}$. Em oposição à teoria MDC, não há aqui um estado comum à percepção e à ilusão. A teoria do conteúdo disjuntivo da percepção permite a explicação da possibilidade da ilusão, a principal motivação para a teoria MDC, sem tornar o acesso ao mundo pela percepção um mistério - na percepção, o sujeito está em contato com o mundo ele mesmo. Se pensarmos que a principal motivação da teoria MDC é a explicação da falibilidade dos sentidos, a teoria disjuntiva é de fato uma boa alternativa. Se o sujeito realmente percebe um fato, então ele está em contato com o fato ele mesmo; se ele estiver errado, ele está num outro estado, isto é, num estado cujo conteúdo não é o mesmo que o conteúdo de um estado perceptual. $\mathrm{O}$ antecedente do condicional cujo conseqüente estabelece o conteúdo do estado cognitivo não é necessariamente conhecido pelo sujeito, que pode assim não saber se está numa ou noutra situação, e, portanto, se enganar em julgamentos que têm origem na experiência.

III

Os argumentos contrários a uma teoria de tipo MDC são convincentes, mas esta recusa não leva necessariamente à concepção disjuntiva do conteúdo da percepção. Meu argumento contra a teoria disjuntiva vai se desdobrar em três mo- 
mentos. Inicialmente, procurarei mostrar que não é certo que a teoria disjuntiva possa ser útil na explicação da experiência perceptiva. O principal interesse deste primeiro movimento argumentativo é chamar a atenção para práticas explicativas efetivas, práticas que não parecem ter um lugar para o conteúdo disjuntivo. Em seguida, a consideração da fenomenologia de uma situação de ilusão cognitiva radical, a alucinação, mostra que nem a teoria disjuntiva, nem a teoria MDC são capazes de explicar o modo como estas experiências aparecem ao sujeito. Esta conclusão parcial deve ser enfraquecida: não apenas é possível que as coisas apareçam ao sujeito de maneira diferente do modo como as apresento, como a fenomenologia ainda não decide o lugar que o conceito de objetividade ocupa na explicação da experiência. Mais uma vez, este movimento argumentativo leva a um terceiro momento, que consiste em delinear o conceito de objetividade da percepção de um modo que não parece ser compatível nem com uma teoria MDC, nem com uma concepção disjuntiva do conteúdo perceptivo.

Quando a explicação de uma ação recorre a uma disjunção do tipo '(há alguma coisa que parece a $S$ ser $F$ ) ou (é para $S$ como houvesse alguma coisa que lhe parece ser F)'? Vamos supor que $S$ ele mesmo deva fazer este julgamento, '(há alguma coisa que parece a mim, $S$, ser $F$ ) ou (é para mim, $S$, como houvesse alguma coisa que me parece ser $F)^{\prime}$ '. Do seu ponto de vista, ex hypothesi, os dois membros da disjunção são indistinguíveis. Um internalista pode observar que uma distinção inacessivel do ponto de vista de $S$ é inútil para S (McDOWELL, 1998, p. 381). Este parece ser também o que visa a observação de Snowdon citada acima: alguém que esteja em dúvida se um julgamento perceptual é verdadeiro estará também em dúvida se ele percebe de fato o que constitui o conteúdo deste julgamento. Não estamos tão longe de uma teoria MDC, pois o sujeito não pode decidir qual membro da disjunção é verdadeiro. Por tudo o que ele sabe, diria um internalista, ele pode estar em qualquer uma das duas situações. Se a teoria disjuntiva permi- 
te a economia de um estado cognitivo neutro e independente da percepção, ela não parece mais capaz de explicar o contato perceptivo com o mundo.

Esta distinção pode certamente ser feita do ponto de vista da terceira pessoa: um intérprete pode dizer se um determinado agente percebe um objeto ou se tem uma alucinação. A distinção pode ser feita, mas a disjunção ela mesma não terá utilidade alguma para o intérprete: sabendo qual membro é verdadeiro (ou pelo menos julgando, do seu ponto de vista, qual membro da disjunção é verdadeiro), não há razão para utilizar a disjunção; ou bem ele dirá 'há alguma coisa que parece a $S$ ser $F$ ', ou bem ele dirá 'é para $S$ como houvesse alguma coisa que lhe parece ser $F$ ', mas não '(há alguma coisa que parece a $S$ ser $F$ ) ou (é para $S$ como houvesse alguma coisa que lhe parece ser F)'. A diferença entre casos em que há engano e casos em que não há engano nunca se apresenta de forma disjuntiva para o intérprete: se engano houver, o intérprete dirá que é para $S$ como se houvesse alguma coisa que lhe parece ser $F$. Na verdade, ele pode dizer outras coisas, por exemplo, que $S$ finge ver um objeto $F$, ou ainda que $S$ finge ter a alucinação de um objeto $F$, mas nenhum destes casos levará a um julgamento na forma disjuntiva acerca do conteúdo da percepção do agente.

Se o conteúdo disjuntivo não pode ser usado do ponto de vista da primeira pessoa (ou pelo menos não tem vantagens em relação à teoria MDC, do ponto de vista da primeira pessoa), e não é necessário do ponto de vista da terceira pessoa, qual sua utilidade? Pode-se dizer que uma razão é a explicação do comportamento comum a um agente que vê um determinado objeto e um agente que apenas tem a impressão de ver um tal objeto. A teoria MDC tem uma explicação direta para o que é comum aos dois tipos de comportamento: o conteúdo da experiência do sujeito é o mesmo. A teoria disjuntiva ela mesma parece capaz de oferecer uma explicação deste tipo. Mas qual é o interesse em se tomar como explanandum o comportamento comum a agentes nestes dois casos? Existe de fato 
um comportamento comum que exija uma explicação uniforme? Do ponto de vista internalista, que se interessa apenas por estados internos ao sujeito, este pode ser um recorte natural da explicação do comportamento. Mas, uma vez que percebemos que a identificação deste explanandum é dependente do quadro teórico internalista, a motivação para a adoção de uma teoria MDC pelo seu poder explicativo deste tipo de explanandum torna-se circular. De fato, do ponto de vista de um intérprete que vê o agente num meio determinado, não há motivo algum para se buscar uma explicação que permaneça neutra quanto ao fato de aquele que se interpreta estar de fato em contato com o mundo ou apenas ter a impressão de estar em contato com o mundo. Esta explicação seria, ao contrário, muito pouco natural.

Pode-se pensar que o recurso a um conteúdo disjuntivo seja útil a um intérprete que esteja ele mesmo em dúvida se o sujeito percebe ou alucina um determinado objeto, por exemplo, por se encontrar longe daquele que interpreta. Aqui começamos a nos aproximar do verdadeiro interesse deste primeiro movimento argumentativo: talvez seja possível construir situações particulares nas quais este tipo de explicação parecerá interessante, mas devemos justamente procurar quais são as situações efetivas de explicação da ação, e portanto de atribuição de conteúdos. Se esta interpretação desengajada do mundo é possível, ela não oferece o modelo para o que é explicar uma ação; ao contrário, nossos conceitos de explicação da ação humana, nos quais a atribuição de um conteúdo determinado a estado cognitivo de um agente aparece, demandam freqüentemente a consideração do agente agindo no mundo que o intérprete ele mesmo percebe. Este é o caso de verbos factivos, como 'ver' ou 'ouvir', mas a mesma conclusão se segue, mais geralmente, dos constrangimentos externos sobre a compreensão do que é agir racionalmente no mundo ${ }^{6}$. Estes conceitos são também os que participam da compreensão, pelo sujeito, de sua própria ação, e, portanto, são constitutivos da auto-atribuição de estados cognitivos com conteúdos determinados. 
O interesse em se distinguir ilusão e percepção é o de explicar, ao mesmo tempo, nossa apreensão do mundo e a possibilidade do erro. O explanandum em torno do qual a teoria MDC se desenvolve, assim como a resposta alternativa que oferece a teoria disjuntiva do conteúdo, não são um elemento central neste debate.

\section{IV}

A primeira parte do argumento traz como lição que devemos examinar situações efetivas de atribuição de estados cognitivos com um conteúdo determinado, para ver como nossos conceitos são efetivos nestas atribuições, e em particular na distinção entre a percepção e a mera aparência de percepção. $O$ segundo momento será o de considerar uma situação particular de atribuição (e de auto-atribuição) de um estado cognitivo particular a um agente, a alucinação. Contrariamente ao que a teoria MDC sugere, do ponto de vista da primeira pessoa, a percepção e a alucinação não são exatamente indistinguíveis, ou pelo menos este não é sempre o caso. $\mathrm{O}$ sujeito que alucina identifica erroneamente a origem do seu percepto: o sujeito tem a experiência da alucinação como tendo origem no mundo, e não em si mesmo, e nisto ela difere, por exemplo, da imaginação. Isto não significa, no entanto, que ele considere a experiência como idêntica a uma experiência de percepção. Embora o sujeito tenha a experiência da alucinação como algo real, ele freqüentemente pensa que o que percebe na alucinação não pode ser percebido por outros, diferentemente do que ele percebe efetivamente. Um sujeito pode ter alucinações auditivas, por exemplo, escutar vozes como vozes reais, e manter uma conversa considerando que seu interlocutor escuta apenas o que é efetivamente pronunciado. Neste tipo de interação, o sujeito que alucina não espera que as vozes alucinadas sejam percebidas pelo outro, e nisto elas são diferentes das vozes reais, que o sujeito espera serem percebidas por seu interlocutor? 
Esta distinção aparece de um ponto de vista fenomenológico. Uma excelente análise do fenômeno alucinatório encontra-se na Phénoménologie de la perception de Maurice Merleau-Ponty. Se o sujeito tem a experiência da alucinação como tendo sua origem no mundo, ela não está no horizonte de suas outras experiências, não mais do que no horizonte de experiências de outras pessoas. Se eu vejo um objeto de um determinado ponto de vista, eu sei que, se ele estivesse numa outra posição, veria o mesmo objeto de maneira diferente, e que uma outra pessoa, de outro ponto de vista, também veria o mesmo objeto;

\begin{abstract}
... as experiências do outro ou aquelas que eu teria deslocandome apenas desenvolvem o que é indicado pelos horizontes da minha experiência atual, e não acrescentam nada. Minha percepção faz coexistir um número indefinido de cadeias perceptuais que a confirmariam sob todos os pontos de vista e concordariam com ela ${ }^{8}$. (MERLEAU-PONTY, 1945, p. 390)
\end{abstract}

$\mathrm{Na}$ alucinação, há uma ruptura da integração das experiências. Esta ruptura não é nem intelectual, nem puramente sensorial, ela diz respeito talvez ao que Gareth EVANS chama de "uma teoria primitiva da percepção" (a

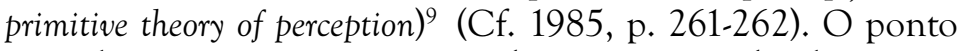
crucial para nós é que, apesar da experiência da alucinação ser uma experiência de algo como real, ela não é parte do mundo do alucinado ele mesmo, ou ainda, de maneira menos metafórica, ela não é vivida pelo sujeito que alucina do mesmo modo que aquilo que ele percebe de fato. $O$ sujeito que percebe efetivamente sabe que, à medida que ele se move, sua percepção do mundo responderá, que um olhar mais atento revelará uma infinidade de detalhes - na bela frase de MERLEAU-PONTY, "je sens pulluler sous mon regard la masse infinie des perceptions plus detaillées que je tiens d'avance et sur lesquelles j'ai prise" (Cf. 1945, p. 390; Cf. também NOË, 2004, p. 64-65). O sujeito que alucina, por sua vez, não tem esta experiência da plenitude 
do mundo: "o sujeito que alucina não tem tal crença: o fenômeno alucinatório não faz parte do mundo, isto é, ele não é acessível, não há caminho definido que leve dele a todas as outras experiências do sujeito que alucina ou à experiência do sujeito são"10 (MERLEAU-PONTY, 1945, p. 390). Do ponto de vista fenomenológico, o que falta, no caso da alucinação, é a rede de expectativas que conecta uma experiência com outras experiências, a acessibilidade de uma experiência a partir de outras experiências relacionadas. Este é um aspecto intrínseco da experiência, diz MERLEAU-PONTY (1945, p. 387), e não um comentário que poderia ser feito do ponto de vista da terceira pessoa.

O que aparece aqui do ponto de vista da primeira pessoa também está presente num julgamento feito do ponto de vista da terceira pessoa:

Se eu considero as vozes e visões de meu interlocutor como alucinações, é porque não encontro nada correspondente no meu mundo visual ou auditivo. Eu tenho então consciência de captar pela audição e sobretudo pela vista um sistema de fenômenos que não constitui apenas um espetáculo privado, mas que é o único possível para mim, e mesmo para o outro, e é isto que nós chamamos real ${ }^{11}$. (MERLEAU-PONTY, 1945, p. 390)

Podemos tirar duas lições desta análise. A primeira lição é que a objetividade do conteúdo está na possibilidade da integração da experiência, das experiências do próprio sujeito e das experiências de diferentes sujeitos, como relativas a uma mesma situação. O sujeito que alucina, pelo menos às vezes, diferencia, ou mais precisamente vivencia de maneira diferente o que ele percebe como pertencendo ao mundo em comum e o que ele alucina, que é acessível apenas a ele, ou ainda o que ele percebe como tendo uma estabilidade à qual sua percepção será sensível, do que ele alucina, que não está integrado com suas diferentes experiências. Do ponto de vista do teórico, pode-se dizer que esta diferença reflete a distinção entre o que é vivido 
como pertencendo a um mundo objetivo e o que não é vivido como pertencendo a um mundo objetivo. Não é necessário que o modo como estas diferenças fenomenológicas aparecem ao sujeito correspondam a conceitos que ele mesmo utilizaria para descrevê-las. Isto é em particular pertinente se pensarmos que partimos de casos nos quais ocorre uma ruptura da conexão das experiências, que se reflete também como uma ruptura dos conceitos aplicados à descrição da própria experiência. Isto explica por que o sujeito que alucina pode, ao mesmo tempo, pensar que sua experiência é real e tem uma origem externa e revelar, pela desintegração de suas expectativas, os aspectos da experiência que são recrutados em usos normais de tais conceitos, ou ainda aquilo a que a normatividade expressa em tais conceitos é sensível.

Esta posição é próxima da teoria davidsoniana da triangulação: a objetividade está precisamente na possibilidade de uma mesma coisa ser objeto da experiência de mais uma pessoa, e de cada sujeito ter a experiência que o outro tem de uma experiência relativa à mesma situação ${ }^{12}$. Merleau-Ponty mostra como esta idéia pode ser acomodada numa abordagem fenomenológica: ter a experiência de algo como pertencendo ao mundo é ter uma experiência de algo que é acessível de outros pontos de vista. Claro que esta experiência é falível, mas esta falha mesma só pode aparecer numa triangulação efetiva (o que inclui a possibilidade da comparação, por um mesmo sujeito, de diferentes experiências relativas a uma mesma situação, ao longo do tempo e em diferentes modalidades). Esta é a fonte da objetividade como parte da experiência do mundo.

Se o interesse em se distinguir a percepção da alucinação está na explicação da objetividade do nosso pensamento, o foco na explicação do comportamento comum entre alguém que perceba algo e alguém que tenha apenas a impressão de perceber algo não é um bom caminho. Mesmo se se conseguir achar um nível adequado de abstração no qual estas duas ações tenham uma explicação comum, este será precisamente um ní- 
vel no qual se perderão os traços que distinguem, tanto do ponto de vista da primeira pessoa quanto do ponto da terceira pessoa, o pensamento objetivo daquele que não o é.

Merleau-Ponty nos mostra que há algo que se perde na fenomenologia mesma da experiência, ao se buscar uma explicação que caberia indistintamente a um agente engajado no mundo e a um agente desengajado, ou que poderia ser feita por um intérprete engajado no mundo e por um intérprete desengajado. A teoria MDC não tem uma motivação fenomenológica real, pelo menos se considerarmos a alucinação como sendo um caso ao qual ela poderia se aplicar; a fenomenologia da alucinação sendo diferente da fenomenologia da percepção, não há razão para se buscar um explanandum que identifique os dois casos, ou em todo caso razão alguma deste tipo virá de considerações fenomenológicas.

Duas objeções podem ainda ser feitas, relativas ao ponto de vista da primeira pessoa: (i) o sujeito que alucina nem sempre é capaz de distinguir suas alucinações de suas percepções, e (ii) mesmo quando o faz, ele julga que suas alucinações têm origem no mundo, e não são o produto de sua própria atividade mental. Estas críticas não atingem, no entanto, o ponto central do argumento. Inicialmente, não se trata de mostrar que a experiência perceptiva e a experiência alucinatória nunca são indistinguíveis - existem casos de erros perceptuais, e não apenas patológicos, nos quais isto ocorre. Trata-se antes de ver que a objetividade da experiência está nas expectativas que ela gera e que ela satisfaz. O que a diferença na fenomenologia da situação normal e da situação patológica nos mostra é que os elementos para a distinção entre o objetivo e o não objetivo, no interior mesmo da experiência, não podem ser vistos numa experiência pontual, mas na rede de experiências possíveis e de experiências reais que caracterizam a experiência vivida como relativa a um mundo objetivo. Em relação à segunda crítica, deve-se responder que a distinção entre o objetivo e o não objetivo pertence ao vocabulário do teórico - basta reconhecer 
que os traços que distinguem uma situação da outra estão presentes na experiência do sujeito, e não são apenas comentários feitos do ponto de vista da terceira pessoa, mesmo se o sujeito ele mesmo não utiliza a noção de objetividade para reconhecer o que distingue uma situação da outra. $O$ horizonte no qual se integram experiências, ou ainda a teoria primitiva da percepção, não são teorias reflexivas que incluiriam conceitos sobre o modo como a noção da objetividade surge a partir da integração da experiência que operam. A resposta a esta segunda objeção já nos coloca no terceiro movimento do nosso argumento: a dificuldade fenomenológica da teoria MDC tem como contrapartida sua incapacidade de construir uma rede conceitual a partir da qual a noção de objetividade, e portanto a distinção entre uma experiência real e a mera ilusão de experiência, pode aparecer.

É difícil encontrar espaço para uma teoria primitiva da percepção, ou para a integração das experiências num horizonte comum, e assim para rupturas desta integração, numa teoria MDC. Mas a teoria disjuntiva do conteúdo não parece se sair muito melhor. Não se pode construir uma teoria disjuntiva do conteúdo da percepção que inclua a rede de expectativas levantadas e satisfeitas pela experiência, ou antes, estas redes serão rapidamente divergentes. Uma teoria do conteúdo da nossa percepção não é uma teoria acerca de um componente isolado, isto é, de um componente tomado independentemente de outras experiências tomadas como relativas a um mesmo objeto ou a uma mesma situação, a outras experiências de si mesmo ou de outra pessoa.

A segunda lição que este percurso fenomenológico sugere, que talvez seja um aspecto da lição anterior, é que devemos considerar o conteúdo da experiência como estendido no tempo. O conceito de objetividade aparecerá mais claramente, ou talvez só poderá aparecer de fato, se, ao invés de focarmos em experiências pontuais (como ver um flash de luz), nos interessarmos ao curso temporal de ações. Nosso argumento até 
aqui visava mostrar que a objetividade da experiência aparece nas expectativas que ela levanta e satisfaz. No caso de engano, as expectativas não serão satisfeitas e, de maneira talvez mais significativa, em algumas situações de alucinação, elas não serão sequer levantadas. Esta conexão de expectativas só pode aparecer no tempo, à medida que a experiência do sujeito cria expectativas em relação ao comportamento dos objetos que a constituem e de outros sujeitos que observam e agem na mesma situação.

O interesse em se perguntar quando o conteúdo disjuntivo da experiência poderia ser útil residia em chamar a atenção para práticas efetivas de explicação da ação, que são estendidas no tempo, e não pontuais. Experiências pontuais não são mais naturais como objetos de explicação do que a ação de um sujeito considerado em abstração do ambiente no qual se encontra. Também do ponto de vista da primeira pessoa, a consideração de um instante isolado não é mais do que um construto teórico. $\mathrm{O}$ mundo nos aparece como tendo tal ou tal aspecto num fluir contínuo da experiência.

O modo como a experiência explica a ação do sujeito, uma ação que vai se desdobrar no tempo, mostra uma importante diferença entre a percepção e a ilusão perceptiva (entendida de maneira geral, de modo a incluir a alucinação). Esta observação segue a tese de Tim Williamson segundo a qual o conhecimento é mais robusto do que a mera crença verdadeira justificada, o que aparece no modo como um e outro figuram na explicação da ação ${ }^{13}$. Se o sujeito sabe que $p$, ele manterá este saber em situações contrafactuais semelhantes à do mundo efetivo, assim como manterá este saber à medida que o tempo passa, ao passo que a crença verdadeira justificada desaparecerá, i.e., deixará de ser justificada ou verdadeira, mais facilmente. Esta diferença aparece claramente no modo como um e outro figuram na explicação da ação. Uma vez feita a distinção, diferentes progressões da ação num e noutro caso saltam aos olhos: basta pensar num dos engenhosos exemplos 
à la Gettier construídos para mostrar a insuficiência de diferentes definições do conhecimento perceptual. É claro que a ilusão será muito menos robusta do que a percepção: em situações contrafactuais próximas do mundo efetivo, assim como na modificação da situação na qual se encontra o sujeito com o passar do tempo, a percepção de um dado objeto se manterá mais facilmente do que a ilusão da percepção. Esta diferença, mais uma vez, terá conseqüências na ação do sujeito.

Um modo diferente de colocar a conclusão do argumento até aqui é que a teoria MDC não permite o reconhecimento da robustez do conhecimento, oposta à fragilidade da alucinação. $\mathrm{O}$ fator comum à alucinação e à percepção desaparece rapidamente, à medida que a ação do sujeito se desenrola, ou ainda em situações contrafactuais próximas do mundo efetivo. Mais uma vez, a teoria disjuntiva do conteúdo perceptivo não parece se sair melhor, os membros da disjunção não têm percursos temporais e modais semelhantes, e portanto a disjunção ela mesma é instável.

A teoria disjuntiva herda da teoria MDC uma imagem da experiência como dividida em instantes isolados, assim como ela herda como explanandum a explicação da ação feita por um intérprete desengajado do mundo. Esta dificuldade exposta do ponto de vista da terceira pessoa, como vimos, tem um correspondente do ponto de vista da primeira pessoa. Não há como reconhecer o que é para nós um pensamento objetivo, sem o ver como parte de uma rede de expectativas relativas a outras experiências, de si mesmo e dos outros.

Embora a teoria disjuntiva da percepção me pareça inadequada para explicar a objetividade do pensamento e da percepção, o abandono da teoria MDC ainda é um objetivo teórico importante. $\mathrm{O}$ passo crucial no abandono da teoria MDC, acredito, está na forma condicional na determinação do con- 
teúdo da experiência. Esta forma condicional aparece no tratamento de McDowell do pensamento singular. Se um sujeito tem um pensamento singular, então o objeto sobre o qual ele tem este pensamento existe, trata-se de um pensamento dependente do objeto. Mas se não há tal objeto, o sujeito tem apenas a ilusão de ter tal pensamento; esta é uma "possibilidade evidente, que se esteja sob a ilusão de se estar numa relação com um objeto que contaria como um contato com o objeto (that would count as acquaintance), a impressão sendo apenas ilusória, porque não há tal objeto" (McDOWELL, 1998, p. 232). Não há conteúdo que poderia ser atribuído a alguém que tenha a impressão de ter um pensamento singular, independentemente do fato deste ter de fato um tal pensamento ou não. Alguém que tenha impressão de ter um pensamento singular tem um pensamento dependente de objeto, se ele tem um pensamento qualquer. A forma condicional evita a atribuição de pensamentos singulares que permaneceria neutra em relação ao mundo, i.e., à existência ou não do objeto, ao mesmo tempo em que reconhece a falibilidade de tais pensamentos (McDOWELL, 1998, p. 390). A forma condicional equivale ao abandono da transparência do objeto do pensamento e da percepção do sujeito, que tem um papel importante, como observei no início do texto, na apresentação da teoria MDC. Não por acaso, McDowell argumenta neste artigo contra Russell, e em particular contra a exigência do contato direto com os constituintes de um pensamento, exigência que equivale à transparência do objeto de pensamento ao sujeito.

De fato, esta forma condicional permite um pensamento dependente de objeto falível. Um pensamento singular existe apenas se o objeto a que ele visa existir. De modo similar, a percepção de um objeto ocorre apenas se o objeto existir, o que é óbvio. Se esta condição mundana não ocorrer, então não há percepção, mas não há tampouco um estado neutro em relação à existência ou não do objeto: o agente está num outro estado que não envolve a existência do objeto - ele alucina, ou 
finge alucinar, ou está sob outro tipo de ilusão cognitiva.

A adoção de uma forma condicional evita a idéia de um estado cognitivo neutro em relação ao mundo, mas não é ela mesma uma teoria da objetividade. A raiz da noção de objetividade não pode ser vista num estado cognitivo isolado, mas na sua integração com outros estados e com ação, na sua acessibilidade a partir de outros estados do mesmo sujeito e a partir do ponto de vista de outros sujeitos. Se o conceito de objetividade aparece apenas na integração de diferentes experiências, esta integração mesma mostra por que não há conteúdo da percepção e do pensamento, ou em todo caso de um pensamento singular, que estivesse igualmente ao alcance do sujeito, quer ele esteja em contato com o mundo, quer ele esteja ou não esteja em contato com o mundo. Esta integração mesma não pode ser realizada e, em alguns casos, sua expectativa sequer aparece, quando o sujeito não percebe de fato uma situação mundana.

Se o abandono de uma teoria MDC é um passo no caminho de reconhecer o modo como nosso pensamento está efetivamente em contato com o mundo, ele não nos leva necessariamente a uma teoria disjuntiva do conteúdo. Talvez a teoria disjuntiva não seja de fato uma teoria, mas um momento dialético no abandono da teoria $\mathrm{MDC}^{14}$. Neste caso, a teoria disjuntiva não é diferente da forma condicional de atribuição de conteúdos, ou ainda as frases condicionais poderiam ser organizadas numa disjunção: se o sujeito realmente percebe um fato, então ele está em contato com o fato ele mesmo, ou, se ele estiver errado, ele está numa outra situação, isto é, uma situação na qual o conteúdo de seu estado cognitivo não é o mesmo que o conteúdo de um estado perceptual. Se este for um modo adequado de apresentar uma teoria disjuntiva da percepção, ela é um passo na direção de uma teoria da objetividade da percepção e do pensamento que evita uma teoria de tipo MDC, mas a teoria da objetividade não terá, no final das contas, uma forma disjuntiva.

Abstract: The idea that there is a content that is common to perception 
and to the mere appearance of perception seems a natural one: to have an illusion is nothing else than to have an experience that is subjectively indistinguishable from perception, and the explanation of this fact by the coincidence of content in both situations comes very easily to the mind. Against this theory of the content of experience, some authors such as P. Snowdon and J. McDowell recommend a disjunctive theory: when it looks to a subject $\mathrm{S}$ that there is an $\mathrm{F}$, then either there is something which looks to $\mathrm{S}$ to be $\mathrm{F}$ or it is to $\mathrm{S}$ as if there is something which looks to him to be an F. I argue that a disjunctive theory of content is not necessary to the refusal of a common content, "available to experience in the deceptive and the non-deceptive cases alike" (McDowell). The first argument is that it is not clear that a disjunctive theory can be of any use either from the first-person point of view or from a third-person point of view. The second point againt a disjunctive theory is that it is unstable: as we consider experience as extended in time, the disjuncts diverge quite clearly. The final argument is that the disjunctive theory is not able to accomodate certain differences between perception and at least certain cases of perceptual illusions.

Key-words: perception, disjunctive content, objectivity, John McDowell

\section{NOTAS}

1 Este texto foi apresentado no colóquio organizado por Hilan Bensusan na UnB, em 2005, e deve muito aos comentários dos participantes, em especial Hilan Bensusan, Manuel de Piñedo e John McDowell. Agradeço também a Dade Bruzzi, pela ajuda bibliográfica.

2 "Thus in every proposition that we can apprehend (i.e. not only in those whose truth or falsehood we can judge of, but in tall that we can think about), all the constituents are really entities with which we have immediate acquaintance". (RUSSELL, 1905, p. 492)

3 "This flouts an idea we are prone to find natural, that a basis for a judgement must be something on which we have a firmer cognitive purchase than we do on the judgement itself ; but although the idea can seem natural, it is an illusion to suppose it is compulsory". (RUSSELL, 1905, p. 492)

4 E esclarecedor aqui considerar a resposta davidsoniana a esta reação cética; este ponto é muito bem apresentado em dois artigos sobre Davidson. (Cf. GENOVA, 1999 e NAGEL, 1999) 
5 "It looks to $S$ as if there is an $F$ : (there is something which looks to $S$ to be $F$ ) $\vee$ (it is to $S$ as if there is something which looks to him (S) to be F)". (SNOWDON, 2002, p. 159)

6 Este é um modo de se apresentar o argumento davidsoniano contra o ceticismo: não há como se entender o comportamento racional de um agente, de lhe atribuir atitudes proposicionais, sem o perceber agindo no mundo, isto é, sem o ver agindo no mundo tal como o intérprete o percebe; ver, por exemplo, DAVIDSON (2001, p. 129-130).

7 Cabaleiro GOAS escreve, sobre a alucinação auditiva, que "muchos hombres-alucinados son capaces de estabelecer diferencias entre lo que es 'alucinatorio' - pese a vivenciarlo como completa realidad y absoluta certeza - y lo que es auténticamente "real"' (1966, p. 631). Sobre os diferentes tipos de alucinação e fenômenos próximos a ela (pseudo-alucinação, alucinose, ilusão etc.), ver GOAS (1966, p. 439-400)'. Ver também Roy VAN DER ZWAARD e Machiel A. POLAK (2001, p. 42-50). Notar que a identificação, na alucinação, do comprometimento do teste de realidade não identifica diferenças fenomenológicas relevantes, como as apontadas por MerleauPonty e por Cabaleiro Goas. Não é sem interesse aqui pensar num contínuo de fenômenos relativos à capacidade representacional, que reúne a percepção, a alucinação e a imaginação; para diferentes desenvolvimentos desta hipótese, ver Ralf-Peter BEHRENDT (1998) e Kai VOGELEY (1999).

8 “... les expériences d'autrui ou celles que j'obtiendrai en me déplaçant ne font que développer ce qui est indiquée par les horizons de mon expérience actuelle et n'y ajoutent rien. Ma perception fait coexister un nombre indéfini de chaînes perceptives qui la confirmeraient en tous points et concorderaient avec elles". Ver também a idéia da presença perceptiva em Alva NOË (2004, p. 59-79).

9 Notar a proximidade entre a idéia de existência não percebida, a que Evans faz referência aqui, e o horizonte das experiências de que fala Merleau-Ponty; o caráter primitivo ou rudimentar da teoria da experiência segundo Evans também se aproxima do que Merleau-Ponty desig- 
na, de modo característico, por uma dupla negação (nem intelectual, nem puramente sensorial).

10 "L’halluciné n'en croit pas tant. Le phénomène hallucinatoire ne fait pas partie du monde, c'est-à-dire qu'il n'est pas accessible, qu'il n'y a pas de chemin défini qui conduise de lui à toutes les autres expériences du sujet halluciné ou à l'expérience des sujets sains".

11 "Si je classe les voix et les visions de mon interlocuteur parmi les hallucinations, c'est que je trouve rien de pareil dans mon monde visuel ou auditif. J'ai donc conscience de saisir par l'ouïe et surtout par la vision un système de phénomènes qui ne constitue pas seulement un spectacle privé, mais qui est le seul possible pour moi et même pour autrui, et c'est là ce qu'on appelle le réel".

12 Ver, por exemplo, "Rational animals" e "The emergence of thought" em DAVIDSON (2001). A idéia da origem da objetividade na integração da experiência, ou na calibração entre diferentes modalidades, é apresentada, num espírito naturalista diferente daquele de Davidson, em Joëlle PROUST (1999); ver também Kai VOGELEY (1999).

13 "Knowledge is superior to mere true belief because, being more robust in the face of new evidence, it better facilitates action at temporal distance." (WILLIAMSON, 2000, p. 101)

14 Este parece ser o caso sobretudo de McDOWELL (comunicação pessoal).

\section{REFERÊNCIAS}

BEHRENDT, Ralf-Peter. Underconstrained perception: a theoretical approach to the nature and function of verbal hallucinations. Comprehensive Psychiatry, 39, p. 236-248, 1998.

CABALEIRO GOAS, Manuel. Temas psiquiátricos: algunas cuestiones psicopatologicas generales. Madrid: Paz Montalvo, 1966.

DAVIDSON, Donald. The emergence of thought. In: Subjective, intersubjective, objective. Oxford: Clarendon, 2001. 
. Rational animals. In: jective, objective. Oxford: Clarendon, 2001.

EVANS, Gareth. Things without the mind. Subjective, intersubpapers. Oxford: Clarendon, 1985.

GENOVA, A. C. The very idea of massive truth. In: HAHN, Lewis E. (ed.) The philosophy of Donald Davidson. The library of living philosophers. v. XXVII. Chicago: Open Court, 1999. p. 167-191.

HINTON, J. M. Visual experiences. Mind, 76, p. 217-227, 1967.

McDOWELL, John. Criteria, defeasibility and knowledge. In: Meaning, knowledge, and reality. Cambridge: Harvard University Press, 1998.

-_-_-_. Singular thought and the extent of the inner space. In: ____ Meaning, knowledge, and reality. Cambridge: Harvard University Press, 1998.

MERLEAU-PONTY, Maurice. Phénoménologie de la perception. Paris: Gallimard, 1945.

NAGEL, Thomas. Davidson's new Cogito. In: HAHN, Lewis E. (ed.) The philosophy of Donald Davidson. The Library of Living Philosophers. v. XXVII. Chicago: Open Court, 1999. p. 195-206.

NOË, Alva. Action in perception. Cambridge: MIT Press, 2004.

PROUST, Joëlle. Mind, space and objectivity in non-human animals. Erkenntnis, 51, p. 45-58, 1999.

RUSSELL, Bertrand. On denoting. Mind, 14, p. 479-493, 1905.

SNOWDON, Paul. Perception, vision and causation. In: NOË, Alva; THOMPSON, Evan (eds.) Vision and mind: selected 
readings in the philosophy of perception. Cambridge: MIT Press, 2002. p. 151-166.

VAN DER ZWAARD, Roy; POLAK, Machiel A. Pseudohallucinations: a pseudoconcept? A review of the validity of the concept, related to associative symptomatology. Comprehensive Psychiatry, 42, p. 42-50, 2001.

VOGELEY, Kai. Hallucinations emerge from an imbalance of self-monitoring and reality modelling. The Monist, 82, p. 629644, 1999.

WILLIAMSON, Timothy. Knowledge and its limits. Oxford: Oxford University Press, 2000. 
